Адрес статьи / To link this article: http://cat.ifmo.ru/ru/2018/v3-i3/158

\title{
Новые горизонты изучения технологий информационного общества
}

\author{
М.А. Бакаев ${ }^{1}$, Н.В. Борисов ${ }^{2,4}$, А.Е. Войскунский ${ }^{3}$, В.П. Захаров ${ }^{2}$, \\ Д.Е. Прокудин ${ }^{2,4}$, И.И. Толстикова ${ }^{4}$, А.Ю. Федосов ${ }^{5}$, А.В. Чугунов ${ }^{4}$ \\ ${ }^{1}$ Новосибирский государственный технический университет, Россия \\ ${ }^{2}$ Санкт-Петербургский государственный университет, Россия \\ ${ }^{3}$ Московский государственный университет им. М.В. Ломоносова, Россия \\ ${ }^{4}$ Университет ИТМО, Россия \\ ${ }^{5}$ Российский государственный социальный университет, Россия \\ bakaev@corp.nstu.ru, vae-msu@mail.ru, hogben.young@gmail.com, \\ Tolstikova_irina@mail.ru, alex_fedosov@mail.ru, chugunov@corp.ifmo.ru
}

\begin{abstract}
Аннотация. В 2018 году в Санкт-Петербурге была проведена очередная XXI международная объединённая научная конференция «Интернет и современное общество» (IMS-2018), которая с 2016 года является базовым научным мероприятием «Недели технологий информационного общества в Санкт-Петербурге». Конференция год от года динамично развивается, отражая динамику развития современного информационного общества. Так, в 2018 году в рамках конференции состоялся Международный семинар «Киберпсихология», на котором была обсуждена проблематика, связанная с видоизменением общения, поведения и деятельности человека в условиях сетевого общества, влиянием информационных и коммуникационных технологий на когнитивное и личностное развитие ребенка и взрослого, а также методологией психологических исследований в пространстве интернета. Данный обзор описывает проведение и результаты конференции.
\end{abstract}

Ключевые слова: информационное общество, Интернет и современное общество, международная конференция, IMS-2018

Вот уже на протяжении двадцати лет не ослабевает интерес многочисленных исследователей к проблематике разработки, использования и воздействия на различные аспекты общественного развития технологий информационного общества. Традиционно таких исследователей объединяет проводимая каждый год Международная объединённая научная конференция «Интернет и современное общество» (Internet and Modern Society, IMS). В 2018 году конференция была проведена в двадцать первый раз. С 2016 года конференция является основным научным мероприятием «Недели технологий информационного общества в Санкт-Петербурге» и включает в себя устоявшиеся тематические направления:

- информационные системы для науки и образования;

- электронное обучение и дистанционные образовательные технологии;

- взаимодействие государства и общества в цифровую эпоху; 
- компьютерная лингвистика и вычислительные онтологии.

В рамках объединённой научной программы Недели были проведены следующие научные мероприятия:

- 30 июня - симпозиум молодых учёных «Киберпространство: перспективные социальноэкономические и гуманитарные исследования». Рабочий язык — русский.

- 31 мая - 2 июня - мероприятия конференции «Интернет и современное общество». Рабочий язык - русский.

- 31 мая - 1 июня - третья международная конференция «Digital Transformation \& Global Society». Рабочий язык - английский.

Все мероприятия проводились в Конгресс-центре Университета ИТМО (Санкт-Петербург, ул. Ломоносова, 9).

Открытие Недели технологий информационного общества прошло 30 мая. Его вёл заместитель председателя организационного комитета конференции «Интернет и современное общество» Прокудин Дмитрий Евгеньевич, доктор философских наук, доцент СанктПетербургского государственного университета, аналитик Университета ИТМО. На открытии с приветственным словом выступили: председатель организационного комитета конференции «Интернет и современное общество» Борисов Николай Валентинович, доктор физикоматематических наук, заведующий кафедрой Санкт-Петербургского государственного университета, директор Центра дизайна и мультимедиа Университета ИТМО и учёный секретарь организационного комитета конференции «Интернет и современное общество» и председатель организационного комитета конференции «Digital Transformation \& Global Society» Чугунов Андрей Владимирович, кандидат политических наук, директор Центра технологий электронного правительства Университета ИТМО. С программой Недели технологий информационного общества участников и гостей познакомил директор конференции «Digital Transformation \& Global Society» Юрий Кабанов.

30 мая в рамках объединённой конференции «Интернет и современное общество» состоялся симпозиум молодых учёных «Киберпространство: перспективные социальноэкономические и гуманитарные исследования», который объединил российских студентов и молодых учёных. За организацию Симпозиума отвечала Груздева Мария, руководитель научного клуба "DiTRes.ITMO", магистрант кафедры управления государственными информационными системами Университета ИТМО.

Организаторы отмечают разносторонний характер выступлений в контексте заявленной тематики Симпозиума, глубину проработки тем выступлений и высокую степень мотивированности и готовности участников к самостоятельным научным исследованиям. С докладами на симпозиуме выступили 16 участников.

Завершала работу первого дня Недели технологий информационного общества в СанктПетербурге объединённая постерная сессия международных конференций DTGS-2018 и IMS-2018. На ней было представлено 28 постерных докладов. Участники и гости в непринуждённой обстановке ознакомились с представленными на плакатах результатами научных исследований, пообщались с авторами, поделились своими мнениями.

31 мая, 1 и 2 июня в рамках конференции «Интернет и современное общество» были проведены следующие секции и круглые столы:

- секция «Культура и технологии. Коммуникативная культура в цифровую эпоху», 31 мая (11 докладов).

Сопредседателями секции были Толстикова Ирина Ивановна, кандидат философских наук, заведующая кафедрой социальных и гуманитарных наук ФТМИ Университета ИТМО, Мамина Раиса Ильинична, доктор философских наук, профессор кафедры философии СанктПетербургского государственного электротехнического университета (СПбГЭТУ "ЛЭТИ") и Голик Надежда Васильевна, доктор философских наук, профессор кафедры культурологии, 
философии культуры и эстетики института философии Санкт-Петербургского государственного университета.

На секции обсуждался широкий круг вопросов, связанных с различной проблематикой, разрабатываемой отечественными учёными и исследователями. Активно развиваются исследования по реконструкции объектов культурного наследия России на основе архивных материалов и представление их в мультимедийных информационных системах с доступом из сети Интернет (например, Соловецкий монастырь, Феодоровский городок).

Важным направлением исследований является систематизация и классификация объектов культурного наследия народов России (на примере орнаментов в монголо-бурятском стиле).

Также в работе семинара обсуждались вопросы теоретического и практического характера по следующим направлениям:

- этикет в информационном обществе: формирование новых моделей этикетной коммуникации в цифровой среде;

- инфоэтика глобальной коммуникации: новые возможности и риски;

- тенденции развития цифровой культуры: концептуальные модели и практики;

- цифровые гуманитарные науки (Digital Humanities) как область междисциплинарных исследований и сфера образования;

- информационные технологии в комплексной системе сохранности библиотечных коллекций.

В докладах участников предлагались пути решения следующих актуальных проблем:

- развитие исследований по истории российской культуры;

- осуществление активного обмена культурными ценностями народов России;

- изучение процессов межкультурного взаимодействия;

- анализ коммуникаций (этикетных; научно-исследовательских; в сфере образования) в цифровой среде с использованием мультимедийных и информационных технологий;

- обоснование цифровой культуры как феномена и концепта;

- разработка и реализация комплексного подхода к оцифровке и сохранности библиотечных коллекций;

- сохранение национальной памяти малых народов через создание базы данных цифровых моделей орнаментальных панно.

В выступлениях указывалось на то, что в теоретическом обосновании тенденций развития коммуникативной культуры и мультимедийных коммуникаций в отечественной литературе отсутствуют серьезные монографические работы (в отличие от зарубежных исследований); есть монографии, посвященные отдельным практикам цифровой культуры, а также большая публикационная активность в виде научных статей, конференций, сетевых периодических журналов, институтов, проектов.

- Круглый стол «Проблемы прикладной лингвистики», 31 мая (10 участников, 5 докладов).

Председателем круглого стола была Комалова Лилия Ряшитовна, доктор филологических наук, старший научный сотрудник, Институт научной информации по общественным наукам РАН, Московский государственный лингвистический университет

Круглый стол «Проблемы прикладной лингвистики» был посвящен широкому ряду проблем на стыке лингвистики, информационных технологий и математики. Упомянутые проблемы носят междисциплинарный характер и их решения крайне востребованы по всему миру в связи с быстрым технологическим развитием цифровой информационной среды. На круглом столе были представлены уникальные доклады ведущих лингвистов МГЛУ, ИНИОН РАН, МГУ 
имени М.В. Ломоносова, Московского исследовательского центра при Департаменте региональной безопасности и противодействия коррупции при Правительстве г. Москвы, а также других исследовательских центров и институтов, изучающих вопросы прикладной и математической лингвистики.

- Секция «Информационные системы для науки и образования», 1 июня (14 докладов).

Сопредседатели секции - Казаков Владислав Витальевич, кандидат технических наук, научный сотрудник Новосибирского государственного университета, Бакаев Максим Александрович, кандидат технических наук, старший научный сотрудник Новосибирского государственного технического университета и Прокудин Дмитрий Евгеньевич, доктор философских наук, доцент Санкт-Петербургского государственного университета, аналитик Центра дизайна и мультимедиа Университета ИТМО.

Современные исследования, результаты которых были обнародованы на этой секции, посвящены проблематике социальных, экономических, гуманитарных и, отчасти, технологических особенностей, привнесённых эпохой «развитого Интернета». Основная объединяющая тема выступлений участников секции - использование сети Интернет и информационнокоммуникационных технологий как инструмента в указанных аспектах. Особенностью инструмента при этом является то, что он диктует человеку и обществу возможность его применения зачастую незапланированной изначально.

Современное развитие информационно-коммуникационных технологий предоставляет широкие возможности по хранению и представлению данных из научной, образовательной и смежных областей. Однако предоставляемые сегодня возможности используются не в полной мере. При стабильном ежегодном значительном приросте открытой информации в сети Интернет и постоянном увеличении количества ресурсов остро ощущается проблема упорядочения, структурирования, категоризации данных, а также контроля и защиты их целостности и качества.

В выступлениях участников предлагались различные методы и подходы в решении следующих проблем:

- развитие технологий искусственного интеллекта в социологии и политике;

- повышение качества человеко-компьютерного взаимодействия;

- развитие технологий обработки текстов на естественных языках и формирование их представления;

- проблемы, связанные с разработкой и внедрением методов и подходов представления данных в научных и образовательных информационных системах. Так, детально были обсуждены вопросы когнитивного представления численных данных с помощью доступных графических инструментов, обеспечения доступности текстовых данных с помощью автоматизированного контекстного анализа и последующей категоризации и классификации текстов, а также обеспечения связности, целостности и качества данных при использовании совместимых форматов и внедрении интероперабельности информационных систем, автоматизированного распознавания источника происхождения данных и определения его надёжности.

Необходимо отметить, что влияние российских учёных на решение задач данного научного направления существенно. Ими были представлены оригинальные передовые методы и подходы представления и обработки информации научного и образовательного профиля. Существующие мировые информационные системы на сегодняшний день не обладают инструментами, аналогичными представленным докладчиками. Ряд российских учёных представил убедительные результаты в сферах моделирования агентного поведения, автоматизированного проектирования человеко-компьютерных интерфейсов, применения нейросетевых моделей и др.

Особо следует отметить ряд докладов молодых учёных, отличившихся глубиной анализа задач, использованием значительных объёмов реальных данных.

International Culture \& Technology Studies, Vol. 3, No. 3 
- Секция «Электронное обучение и дистанционные образовательные технологии», 2 июня (6 докладов).

Сопредседатели сессии были Федосов Александр Юрьевич, доктор педагогических наук, профессор кафедры информатики и прикладной математики Российского государственного социального университета и Прокудин Дмитрий Евгеньевич, доктор философских наук, доцент Санкт-Петербургского государственного университета, аналитик Центра дизайна и мультимедиа Университета ИТМО.

Проблема развития электронного обучения и внедрения дистанционных образовательных технологий в отечественном образовании рассматривалась докладчиками в аспекте различных направлений, в частности:

- разработки электронных средств обучения (учебников, интерактивных учебных пособий, систем диагностики уровня обученности и достижения образовательных результатов), призванных повысить эффективность самостоятельной работы обучающихся, дать мотивирующий импульс к созидательному и активному освоению учебного материала;

- подготовки учебных дисциплин на основе применения различных электронных средств обучения;

- разработки новых образовательных программ, реализация которых направлена на подготовку кадров для цифровой экономики и включает активное применение дистанционных образовательных технологий.

В докладах была затронута следующая проблематика:

- повышение эффективности применения средств электронного обучения в образовательном процессе университета;

- устранение терминологической неопределённости понятий в области электронного обучения;

- теоретическое обоснование и практическая реализация новых методов диагностики достижения образовательных результатов, ориентированных на учёт индивидуальных особенностей и способностей обучаемых;

- построение адекватной модели обучаемого при разработке электронных образовательных технологий;

- поиск новых методов и форм организации учебного процесса, направленных на формирование информационной компетентности его участников;

- подготовка кадров для сферы дистанционного обучения.

Представленные на секции доклады показывают, что отечественные учёные и практики в полной мере способны найти пути решения поставленных проблем и реализовать уже существующие результаты в данной области. Также было отмечено, что проблема подготовки научных кадров в области электронного обучения исключительно важна, остро стоит вопрос разработки новых учебных программ, в первую очередь магистерских, и модернизации существующих образовательных программ бакалавриата в части профессиональных дисциплин в отношении расширения образования инженерных и педагогических кадров в соответствующей области теории и методики.

- Секция «Взаимодействие государства и общества в цифровую эпоху», 2 июня (11 докладов).

Сопредседатели секции - Сморгунов Леонид Владимирович, доктор философских наук, Санкт-Петербургский государственный университет, Соколов Александр Владимирович, кандидат политических наук, Ярославский государственный университет им. П.Г. Демидова, Чугунов Андрей Владимирович, кандидат политических наук, Университет ИТМО и Болгов Радомир Викторович, кандидат политических наук, Санкт-Петербургский государственный университет. 
Секционное заседание проходило в 2-х частях: первая часть проводилась как мероприятие Исследовательского комитета Российской ассоциации политической науки (РАПН) по сравнительной политологии, вторая - Исследовательского комитета РАПН «ИКТ и политика». Мероприятия проводились при поддержке исследовательских проектов РФФИ («Гражданское участие в условиях формирования цифрового правительства», 2018-2020, рук. Л.В. Сморгунов) и РНФ (Электронное участие как фактор динамики политического процесса и процесса принятия государственных решений, 2018-2020, рук. А.В. Чугунов).

Проблематика, связанная с теорией и практикой взаимодействия власти и общества в электронной среде, рассматривалась в следующих аспектах:

- цифровые трансформации в современном обществе и их воздействие на глобальное и государственное управление;

- концептуализация понятий и модели электронного управления;

- электронное участие и специфика взаимодействия граждан и власти на региональном уровне;

- партисипаторное бюджетирование как один из механизмов электронного участия и влияния граждан на формирование политики распределения средств на местном уровне;

- методы и технологии определения эффективности функционирования порталов электронного участия;

- образ «умного города» в средствах массовой информации.

В докладах были затронуты следующие теоретические проблемы, а также вопросы разработки инструментария для проведения эмпирических исследований в сфере электронного управления:

- отсутствие в российской политической науке общепризнанных определений и понятий «электронное управление» (E-Governance), «электронное участие» (E-Participation);

- актуальность разработки комплексной методологии исследования площадок электронного взаимодействия власти и общества;

- важность апробации и применения для научных исследований инструментария общего доступа (Google Analytics, Яндекс метрика и др.);

- необходимость создания специализированного компьютерного инструментария, позволяющего анализировать работу площадок электронного участия разных типов и институциональной принадлежности;

- актуальность применения методов сетевого и семантического анализа для осуществления комплексных и локальных эмпирических исследований в сфере электронного управления и электронного участия;

- отсутствие четко сформулированного и научно-обоснованного набора показателей и индикаторов, позволяющих оценить эффективность площадок электронного взаимодействия власти и граждан.

В 2018 году в составе объединённой конференции были проведены международные научные семинары «Киберпсихология» и «Компьютерная лингвистика».

Международный семинар «Киберпсихология» (Internet Psychology — IntPsy-2018) прошёл с 1 по 2 июня как совместное мероприятие конференций «Интернет и современное общество» (IMS-2018 рабочий язык - русский, 9 докладов) и «Digital Transformation \& Global Society» (DTGS-2018, рабочий язык - английский).

Цель научного семинара - создание площадки для обсуждения научным и экспертным сообществом проблематики, связанной с видоизменением общения, поведения и деятельности человека в условиях сетевого общества, влиянием информационных и коммуникационных технологий на когнитивное и личностное развитие ребенка и взрослого, а также методологией психологических исследований в пространстве интернета.

International Culture \& Technology Studies, Vol. 3, No. 3 
Ключевые направления и темы международного семинара:

- методологические проблемы проведения психологических исследований в интернете;

- психология общения, опосредствованного социальными сетями и другими коммуникативными онлайн-ресурсами;

- психология геймера и киберспортсмена;

- сетевая идентичность и виртуальная самопрезентация;

- профессиональная деятельность в высокотехнологичной информационной среде;

- влияние информационных технологий на психическое развитие и социализацию детей и подростков;

- клинико-психологические аспекты взаимодействия человека с высокотехнологичной информационной средой;

- методы и технологии оказания психологической помощи в киберпространстве;

- познание онлайн: психологические аспекты применения интернет-технологий в образовании;

- системы виртуальной и дополненной реальности в психологии;

- информационная культура и информационная безопасность личности.

Сопредседатели семинара - Войскунский Александр Евгеньевич, кандидат психологических наук, старший научный сотрудник, Московский государственный университет им. М.В. Ломоносова, Anthony FAIOLA, The University of Illinois at Chicago, United States, Королева Наталья Николаевна, доктор психологических наук, профессор, заведующая кафедрой психологии профессиональной деятельности РГПУ им. А.И. Герцена, Алехин Анатолий Николаевич, доктор медицинских наук, профессор, заведующий кафедрой клинической психологии РГПУ им. А.И Герцена и Проект Юлия Львовна, кандидат психологических наук, доцент кафедры психологии профессиональной деятельности Российского государственного педагогического университета им. А.И. Герцена.

31 мая с ключевым докладом семинара «The Rise of the Health Information Society? Empowering People by Connecting Mobile Health to Healthy Lifestyle Management» выступил Anthony FAIOLA (The University of Illinois at Chicago, United States).

Для участия в семинаре с докладами на английском языке и последующей публикацией статей было подано 19 заявок. В процессе тройного слепого рецензирования зарубежными и отечественными экспертами из соответствующих областей было отобрано 11 докладов.

На семинаре была представлена широкая панорама исследований в области киберпсихологии, в том числе психологии геймерства, влияние технологий на когнитивное развитие, человеческие факторы при применении систем виртуальной реальности, психологопедагогические проблемы «цифрового образования». Докладчиками были предложены пути решения следующих проблем: влияние цифровых технологий на сознание, когнитивные и личностные характеристики, коммуникативные процессы, интерпретации новых феноменов в области применения технологий виртуальной и дополненной реальности; разработка психологического обеспечения новых информационных технологий в электронной среде. Участниками было отмечено, что исследования в области киберпсихологии ведутся в контексте исследований, характеризующих международное научное сообщество. Также участники пришли к мнению, что для данного научного направления необходима целенаправленная подготовка научных и педагогических кадров, в том числе высшей квалификации, а также организационные решения по совершенствованию материально-технической базы исследований.

Международный семинар «Компьютерная лингвистика» (Computational Linguistics CompLing-2018) прошёл с 1 по 2 июня 2018 г. как совместное мероприятие конференций 
«Интернет и современное общество» (IMS-2018 рабочий язык - русский, 16 докладов) и «Digital Transformation \& Global Society» (DTGS-2018, рабочий язык - английский).

Цель научного семинара - обсуждение актуальных вопросов взаимодействия лингвистики и информационных технологий — как в части развития технологических решений на базе естественного языка, так и в части влияния информационных технологий на язык. Целевой аудиторией являются лингвисты всех профилей, сотрудники организаций, разрабатывающих в внедряющих информационные системы, связанные с обработкой естественного языка, специалисты по представлению знаний, преподаватели вузов, переводчики.

Ключевые направления и темы международного семинара:

- компьютерное моделирование естественного языка;

- компьютерный анализ текстов на естественном языке;

- корпусная лингвистика;

- компьютерные лингвистические ресурсы;

- компьютерные и лингвистические онтологии;

- автоматическое извлечение знаний;

- компьютерный анализ документов;

- автоматизированный информационный поиск;

- машинный перевод;

- компьютерная лексикография;

- речевые технологии;

- лингвистический анализ социальных сетей.

Сопредседателями семинара были Захаров Виктор Павлович, кандидат филологических наук, доцент кафедры математической лингвистики Санкт-Петербургского государственного университета, Хохлова Мария Владимирвона, кандидат филологических наук, СанктПетербургский государственный университет, Азарова Ирина Владимировна, доцент, кандидат филологических наук, Санкт-Петербургский государственный университет и Митрофанова Ольга Александровна, доцент, кандидат филологических наук, Санкт-Петербургский государственный университет.

Для участия в англоязычном семинаре с докладами и последующей публикацией статей было подано 18 заявок. В процессе тройного слепого рецензирования зарубежными и отечественными экспертами из соответствующих областей было отобрано 9 докладов.

Компьютерная лингвистика сегодня - динамически развивающаяся наука. Разработка систем автоматизированной обработки текста и речи является одной из фундаментальных задач современного информационного общества. Создание и использование компьютерных лингвистических ресурсов востребовано в самых разных приложениях. Об активности и востребованности компьютерной лингвистики свидетельствует большое число национальных и международных исследовательских проектов, ежегодных крупных международных конференций в этой области, специализированных научных журналов, образовательных проектов в рамках научных школ-семинаров и т.П., открытие отделений компьютерной лингвистики и прикладной лингвистики в стране.

Аффилиация докладчиков показывают широту распространенности исследований по компьютерной лингвистике у нас в стране. Следует отметить, что среди докладчиков были как профессора, так и студенты. Доклады, сделанные на семинаре, отражают широкую тематику исследований по компьютерной лингвистике: семантика, онтологии, корпусные исследования, морфология, синтаксис, исследования устной речи и речевой деятельности.

Проблемы, освещенные на конференции, имеют как теоретическое, так и прикладное значение. Важное место во всех докладах занимала проблема оценки качества и достоверности

International Culture \& Technology Studies, Vol. 3, No. 3 
данных, получаемых в ходе исследований. Семинар показал, что с помощью компьютерной лингвистики многие проблемы решаются на совершенно новом уровне: появляются новые теоретические концепции, повышается качество словарей и грамматик, разрабатываются модули обработки естественного языка для многих практических задач и т.д.

В мире компьютерная лингвистика сложилась в 1960-е годы. В России (СССР) это направление долгие годы развивалось успешно. В последние годы компьютерная лингвистика стала широко применяться для решения практических задач, связанных с обработкой естественного языка. Россия встала на этот путь с некоторым опозданием, но движется по нему очень быстро. Конференция продемонстрировала значительные успехи российской компьютерной лингвистики в создании корпусов текстов и устной речи, в создании ресурсов и разработке программного обеспечения для обработки русского языка.

Достижения российской компьютерной лингвистики были показаны в докладах, представленных на конференции. Всё это позволяет говорить о хорошей обеспеченности данного направления кадрами. Оборудование также не является препятствием в развитии данного направления.

Принятые материалы участников двух международных семинаров были направлены для публикации в:

- сборнике научных статей "Компьютерная лингвистика и вычислительные онтологии". Выпуск 2 (на русском языке), сериальное издание (ISSN 2541-9781). Индексируется в РИНЦ;

- сборнике научных статей "Информационное общество: образование, наука, культура и технологии будущего". Выпуск 2 (на русском языке), сериальное издание (ISSN 25878557). Индексируется в РИНЦ;

- сборнике материалов конференции DTGS (на английском языке), серия "Communications in Computer and Information Science" (издательство Springer), индексируется в Scopus.

В завершении работы конференции были подведены итоги работы секций и круглых столов, а также состоялась заключительная междисциплинарная дискуссия, на которой обсуждались основные направления научных исследований и разработок для включения их в научную программу следующей конференции «Интернет и современное общество», которую намечено провести в 2019 году (планируемые даты: 20 - 22 июня).

В рамках объединенной научной программы была проведена международная конференция «Цифровые трансформации и глобальное общество» (Digital Transformations \& Global Society DTGS), которая прошла с 31 мая по 1 июня. Конференция организована совместно Университетом ИТМО и НИУ «Высшая школа экономики» (Санкт-Петербург). Главная цель конференции создание представительной площадки для академического и профессионального обсуждения современных тенденций развития информационного общества, что уже подтверждено большим интересом к ней и высоким уровнем участников. Основной темой конференции стали вопросы информационных, социальных, экономических, политических и культурных изменений, связанных с развитием цифровых технологий.

Мероприятия Недели технологий информационного общества освещены в анонсах и репортажах на портале Университета ИТМО:

- Неделя технологий информационного общества (http://news.ifmo.ru/ru/announce/41384/);

- Неделя технологий информационного общества: что такое электронная демократия и как цифровизация меняет гуманитарные науки (http://news.ifmo.ru/ru/education/official/news/7573/);

- Электронная демократия в действии: почему растет количество электронных петиций и как повысить их эффективность (http://news.ifmo.ru/ru/startups_and_business/initiative/news/7591/). 
Для участия в конференции IMS с докладами и последующей публикацией статей или тезисов было подано 193 заявки. В процессе рецензирования экспертами из соответствующих областей было отобрано 117 докладов, доля принятых докладов составила 60\%. На конференции было представлено 109 докладов (8 докладов не было заслушано и тексты статей и тезисов не были включены в соответствующие сборники).

Важным позитивным аспектом явился объединенный характер научных мероприятий и возможность участия как в IMS (на русском языке), так и в секциях и семинарах международной конференции DTGS (на английском языке). Всего в мероприятиях объединенной научной программы приняло участие 187 зарегистрированных участников.

В докладах участников были представлены промежуточные результаты научных исследований, поддержанных научными фондами:

- Российский фонд фундаментальных исследований - 21 доклад (проекты №№: 17-3201087 a, 18-011-00923, 16-37-60060 мол_а_дк, 18-011-00977, 17-29-09159, 16-06-00497, 1607-01180, 16-06-00529, 17-01-00139, 17-29-09173 офи_м, 15-29-07112, 16-37-60094, 16-0700910, 18-011-00929 а, 17-02-12009 в, 17-04-12034, 16-36-60035, 18-011-00756, 18-01100140 a, 16-03-00394 a, 18-011-00705);

- Российский научный фонд - 8 докладов (проекты №№: 16-11-10352, 14-18-03434, 18-1800365, 17-18-01326, 18-18-00477, 14-18-03434, 17-78-10079, 18-18-00360);

- Deutscher Akademischer Austauschdienst (DAAD) - 1 доклад (проекты №№: 56268450, 57271274).

Также были представлены результаты исследований, выполняемых в рамках:

- государственного задания Минобрнауки России № 2.2939.2017/4.6;

- госзадания ФАНО РФ 0159-2018-0003;

- гранта Президента Российской Федерации для государственной поддержки молодых российских ученых № МК-2513.2018.6.

К основным результатам конференции «Интернет и современное общество» в 2018 году можно отнести то, что были предложены и обсуждены различные подходы, тем или иным образом связанные с трансформацией различных областей человеческой деятельности под воздействием информационно-коммуникационных технологий. В том числе были затронуты вопросы изменения жизни людей в условиях перехода к шестому экономическому укладу. Предложенные в докладах результаты исследований и разработок могут быть использованы в развитии отечественной науки, образования, культуры, социальной политики и других системообразующих элементов современного социума.

\section{Литература}

[1] Информационное общество: образование, наука, культура и технологии будущего. Выпуск 2 (Труды XXI Международной объединенной конференции «Интернет и современное общество, IMS-2018, СанктПетербург, 30 мая - 2 июня 2018 г. Сборник научных статей). - СПб: Университет ИТМО, 2018. $336 \mathrm{c}$.

[2] Компьютерная лингвистика и вычислительные онтологии. Выпуск 2 (Труды XXI Международной объединенной конференции «Интернет и современное общество, IMS-2018, Санкт-Петербург, 30 мая - 2 июня 2018 г. Сборник научных статей). - СПб: Университет ИТМО, 2018. - 164 с.

[3] Государство и граждане в электронной среде. Выпуск 2 (Труды XXI Международной объединенной конференции «Интернет и современное общество, IMS-2018, Санкт-Петербург, 30 мая - 2 июня 2018 г. Сборник научных статей). - СПб: Университет ИТМО, 2018. - 132 с.

[4] Интернет и современное общество: сборник тезисов докладов [Электронный ресурс] / Труды XXI Международной объединенной научной конференции «Интернет и современное общество» (IMS-2018), Санкт- Петербург, 30 мая -2 июня 2018 г. — Электрон. дан. - СПб: Университет ИТМО, 2018. - 123 с. Режим доступа: http://ojs.ifmo.ru/index.php/IMS/issue/view/34, свободный. - Загл. с экрана.

International Culture \& Technology Studies, Vol. 3, No. 3 


\title{
New Horizons in the Study of Information Society Technologies
}

\author{
M.A. Bakaev ${ }^{1}$, N.V. Borisov ${ }^{2,4}$, A.E. Voiskounsky ${ }^{3}$, V.P. Zakharov ${ }^{2}$, \\ D.E. Prokudin ${ }^{2,4}$, I.I. Tolstikova ${ }^{4}$, A. Yu. Fedosov', A.V. Chugunov ${ }^{4}$ \\ ${ }^{1}$ Novosibirsk State Technical University, Russia \\ ${ }^{2}$ Saint-Petersburg State University, Russia \\ ${ }^{3}$ Moscow state University. M. V. Lomonosov, Russia \\ ${ }^{4}$ ITMO University, Russia \\ ${ }^{5}$ Russian State Social University, Russia \\ bakaev@corp.nstu.ru, vae-msu@mail.ru, hogben.young@gmail.com, \\ Tolstikova_irina@mail.ru, alex_fedosov@mail.ru, chugunov@corp.ifmo.ru
}

\begin{abstract}
In 2018, the regular XXI international joint scientific conference "Internet and modern society" (IMS-2018) was held in St. Petersburg, which since 2016 is the basic scientific event of the "Information Society and Technology Week in St. Petersburg". The conference is developing dynamically from year to year, reflecting the dynamics of the modern information society. Thus, in 2018, within the framework of the conference, an international seminar "Cyberpsychology" was held, which discussed issues related to the modification of communication, behavior and human activity in a network society, the impact of information and communication technology on the cognitive and personal development of children and adults, as well as the methodology of psychological research in the Internet space. The review describes the discussion on the conference and its results.
\end{abstract}

Keywords: information society, Internet and modern society, international conference, IMS-2018

\section{References}

[1] Information society: education, science, culture and technologies of the future. Issue 2 (Proceedings of the XXI international joint conference " Internet and modern society, IMS-2018, St. Petersburg, may 30-June 2, 2018 Collection of scientific articles). - St. Petersburg, ITMO University, 2018. - 336 p.

[2] Computational linguistics and computational ontologies. Issue 2 (Proceedings of the XXI international joint conference " Internet and modern society, IMS-2018, St. Petersburg, may 30-June 2, 2018 Collection of scientific articles). - St. Petersburg, ITMO University, 2018. - 164 p.

[3] State and citizens in the electronic environment. Issue 2 (Proceedings of the XXI international joint conference " Internet and modern society, IMS-2018, St. Petersburg, may 30-June 2, 2018 Collection of scientific articles). - St. Petersburg, ITMO University, 2018. - 132 p.

[4] Internet and modern society: collection of abstracts. Proceedings of the XXI international joint scientific conference "Internet and modern society" (IMS-2018), St. Petersburg, may 30 - June 2, 2018. St. Petersburg, ITMO University, 2018. - 123 p. - Available at: http://ojs.ifmo.ru/index.php/IMS/issue/view/34. 